\title{
Clustering of infant deaths among Nigerian women: investigation of temporal patterns using dynamic random effects model
}

\author{
Joshua O. Akinyemi ${ }^{1,2^{*}}$ (D, Clifford O. Odimegwu', Olufunmilayo O. Banjo ${ }^{1,3}$ and Babatunde M. Gbadebo ${ }^{2}$
}

\author{
* Correspondence: odunjoshua@ \\ gmail.com \\ 'Demography and Population \\ Studies Programme, Schools of \\ Public Health and Social Sciences, \\ University of the Witwatersrand, \\ Johannesburg, South Africa \\ ${ }^{2}$ Department of Epidemiology and \\ Medical Statistics, Faculty of Public \\ Health, College of Medicine, \\ University of Ibadan, Ibadan, Nigeria \\ Full list of author information is \\ available at the end of the article
}

\begin{abstract}
This study was conducted to estimate the magnitude of infant death clustering as well as the mortality risk associated with death of a preceding child and investigate how these have changed over three decades (1980-2013) in Nigeria. Birth history data from the Nigeria Demographic and Health Survey for 1990, 2003, 2008 and 2013 were analysed using dynamic random effects models. The effect of death of an immediate preceding child (sibling mortality correlation) was estimated by controlling for background characteristics and unobserved heterogeneity.

A total of 232,090 single births to 56,123 women were analysed. Results showed that $13.2 \%$ in the oldest maternal cohort ( $\leq 1969)$ experienced death of at least two infants and they accounted for $40.2 \%$ of all infant deaths. Among the 1970-1979 maternal cohort, it was $8.6 \%$ and $31.6 \%$ respectively. In the youngest maternal cohort ( $\geq 1980), 3$. $3 \%$ had recorded multiple infant deaths but accounted for $20.3 \%$. Model results revealed that sibling mortality correlation increased the probability of infant death by 0 . 080 and 0.061 in the 1980-1989 and 2010 birth cohorts respectively.

There is a substantial level of infant death clustering in Nigeria, and this is closely driven by sibling mortality correlation both of which have declined very slowly over time. To achieve desired progress in child survival, death clustering should be addressed alongside other barriers to child survival.

Keywords: Infant mortality, Death clustering, Death concentration, Preceding child, Sibling mortality correlation, Dynamic models, Nigeria
\end{abstract}

\section{Introduction}

As a reflection of the global progress, the annual rate of under-five mortality reduction in sub-Saharan Africa (SSA) peaked at 4.1\% during 2000-2015 compared to $1.6 \%$ in 1990-2000 (UNICEF, 2015). If current trends persist globally, 47 countries may not meet the Sustainable Development Goal (SDG) target of 25 deaths per 1000 live births by year 2030 (UNICEF, 2015). Thirty-four of these 47 countries are in SSA. Therefore, the rate of under-five mortality reduction must be accelerated to meet the SDG targets. This is very important especially in those countries with high fertility and population growth rates. One of the potential threats to the global efforts to accelerate childhood mortality reduction is a phenomenon called "death clustering". In simple terms, childhood death clustering refers to the concentration of child deaths among certain women (Sastry, 1997b). Although it has been of research interest for some time, it was

(c) The Author(s). 2019 Open Access This article is distributed under the terms of the Creative Commons Attribution 4.0 International License (http://creativecommons.org/licenses/by/4.0/), which permits unrestricted use, distribution, and reproduction in any medium, provided you give appropriate credit to the original author(s) and the source, provide a link to the Creative Commons license, and indicate if changes were made. 
first introduced into the demographic literature in the early 1990s (Das Gupta, 1990). Since then, it has been investigated using varieties of methodological approaches contingent on the type and source of data.

Childhood deaths could be clustered in certain women because children born to the same woman may share genetic, household and community characteristics. The factors found to influence childhood death clustering in mothers/families are also related to the established bio-demographic and socio-economic determinants of childhood mortality which include short birth spacing, poverty and maternal education among others (Omariba, Beaujot, \& Rajulton, 2007; Sastry, 1997a). At the community, levels are socio-cultural norms that affect child healthcare and environmental characteristics such as the source of drinking water, sanitation and access to healthcare (Sastry, 1997a; Zenger, 1993). Several authors most of whom analysed data from health and demographic surveillance systems have also reported child death clustering from clusters of communities/villages (Adjuik, Kanyomse, Kondayire, Wak, \& Hodgson, 2010; Alabi, Baloye, Doctor, \& Oyedokun, 2016; Awini, Mattah, Sankoh, \& Gyapong, 2010; Lutambi, Alexander, Charles, Mahutanga, \& Nathan, 2010; Van Bodegom, Eriksson, Houwing-Duistermaat, \& Westendorp, 2012). Few of these also identified poor infrastructural and environmental characteristics as the main predictors of spatial clustering of child mortality (Alabi et al., 2016; Awini et al., 2010).

With advancement in statistical methodologies which has continued to enhance empirical investigation and better understanding about childhood death clustering, explanations of the processes culminating in the phenomenon have evolved over the past two decades (Edvinsson \& Janssens, 2012). One of the mechanisms that have been proposed to underlie death clustering is the higher risk of child mortality associated with death of a preceding child. Previously, this has been lumped together with the effect of unobserved variables (unobserved heterogeneity). It is now empirically feasible to investigate the mortality risk associated with death of the preceding child (or sibling mortality correlation) while controlling for unobserved heterogeneity. This requires the use of dynamic/transition models which take advantage of the sequence of births or deaths among children born to a woman. To date, the technique has been applied to single cross-sectional data from three developing countries-India (Arulampalam \& Bhalotra, 2006, 2008), Kenya (Omariba, Rajulton, \& Beaujot, 2008) and Bangladesh (Saha \& van Soest, 2011). Infant death clustering was found to be high in 13 out of the 15 states in India (Arulampalam \& Bhalotra, 2008). Sibling mortality correlation raised the risk of infant death by $29 \%$ and $40 \%$ in Bangladesh and Kenya respectively. Infant death clustering tends to be common in high fertility settings (Sastry, 1997a). Therefore, it is worthwhile to replicate studies on death clustering in different countries especially where fertility and childhood mortality remained high.

Furthermore, there is a suspicion that childhood mortality reduction could be stalled where death clustering is prevalent (Arulampalam \& Bhalotra, 2008). Although it is expected that childhood death clustering should decline with mortality levels, however, there is no conclusive evidence on the temporal pattern of infant death clustering and sibling mortality correlation in sub-Saharan Africa where childhood mortality rates are among the highest globally. Empirical evidence on the temporal trends in infant death clustering is very important for policies and programmes on child survival. The present study seeks to address this gap and provide further insights into 
the temporal structure of sibling mortality correlation as a potential explanation for infant death clustering in Nigeria.

Nigeria is one of the most populous countries in sub-Saharan Africa with very slow progress in child survival (Akinyemi, Adebowale, Bamgboye, \& Ayeni, 2015; UNICEF, 2015). Fertility has remained stagnated at above 5 children per woman since 1980s. This is not surprising because contraceptive prevalence has remained very low (Alkema, Kantorova, Menozzi, \& Biddlecom, 2013). There is a wide differential in under-five mortality rates across the six geo-political regions, though partly attributed to socio-economic factors (Adedini, Odimegwu, Imasiku, Ononokpono, \& Ibisomi, 2014b; Akinyemi, Bamgboye, \& Ayeni, 2013). Several intervention programmes have been implemented to address issues related to child survival. These programmes cover topical issues such as child nutrition, immunisation and management of childhood illnesses. Though some progress has been made in the last one decade, mortality and other child health indicators are still below desired levels (Winter, Akinlo, \& Florey, 2016).

Previous studies have identified individual-, household- and community-level determinants of childhood mortality (Adedini, Odimegwu, Imasiku, \& Ononokpono, 2014a; Akinyemi et al., 2015; Antai \& Moradi, 2010), but death clustering has not been previously explored. Reports from an operational research study conducted in three Northern states of Nigeria (Jigawa, Yobe and Zamfara) revealed that more than $80 \%$ of child deaths were reported by only $20 \%$ of the women studied (Klouda \& Adamu, 2013). Similarly, analysis of the 2011-2013 data from Nahuche Health and Demographic Surveillance System (HDSS) in Zamfara State, North West Nigeria, revealed that about one third of under-five deaths were contributed by only $5 \%$ of all households in the HDSS (Alabi, Oyedokun, Doctor, \& Adedini, 2017). In addition, the authors also confirmed the effects of many determinants of under-five mortality. These two Nigeria studies on childhood death clustering did not estimate the contribution of death of a preceding sibling to infant mortality neither was the data robust enough to investigate temporal changes in infant death clustering and sibling mortality correlation.

Given the fact that infant death clustering is common in high fertility settings Arulampalam \& Bhalotra, 2008), Nigeria is a suitable setting to further explore the phenomenon. Therefore, this study is aimed at addressing the following objectives: (i) to estimate the magnitude of infant death clustering among women and effect of death of a preceding child (sibling mortality correlation) in Nigeria and (ii) to investigate how these phenomena have changed over three decades. The main hypothesis investigated was that sibling mortality correlation is a significant contributor to infant death in Nigeria.

\section{Literature overview}

A survey of the literature revealed that most of the explanations for death clustering are closely connected to the proximate and distal determinants of childhood mortality.

These factors which are associated with concentration or clustering of child deaths could be observed or unobserved (unmeasured during data collection) depending on the study design and data collection instrument. Besides, they could operate at individual (child or mother), family (household) and community levels (Adedini et al., 2014b; Antai \& Antai, 2008). Based on these premises, previous studies have estimated child death clustering using different approaches depending on the available data. The most 
common type of data employed has been based on birth histories of women aged 15-49 years which are often collected during Demographic and Health Surveys (DHS) in many developing countries.

One analytical approach is that in which childhood death clustering is estimated as the excess observed deaths over the expected (Das Gupta, 1990; Ronsmans, 1995). Expected deaths are modelled using binomial or negative binomial models based on an underlying assumption that the risk of child death is the same for all women (or families). Unfortunately, this assumption is sometimes not true. Another weakness of the approach is the inability to investigate how the mortality of children in the same family affects inter-family variations (Zaba \& David, 1996).

The second analytical technique which has so far been the most popular was developed around the concept of "unobserved heterogeneity" and has been used to infer death clustering. The idea emanates from the notion that death clustering implied wide variations in the distribution of child deaths between families. Death clustering was therefore estimated as the "unobserved heterogeneity" after all measurable/observed predictors of child death have been controlled. For example, see Madise, Mathews, and Whitworth (2014); Omariba et al. (2007); and Sastry (1997b). One limitation of the approach is that it mixed up death clustering in families/women with "unobserved heterogeneity" which could be at the level of the mother, household or community. Besides, correlated mortality risks among infants born to the same mother are not specifically controlled. Death clustering and unobserved heterogeneity are separate empirical concepts as demonstrated in some later studies (Arulampalam \& Bhalotra, 2008; Saha \& van Soest, 2011).

Two other measures proposed for child death clustering were proportion of children dead out of all births to a woman and a binary measure for multiple deaths (Kuate-Defo \& Diallo, 2002). These have been subjected to linear and logistic regression respectively in order to identify the determinants of death clustering (Kuate-Defo \& Diallo, 2002). Though simple and logical, the measures did not permit the investigation of shared dependence in the risk of death among children born to the same woman.

Other methodological studies argued that child death clustering is largely driven by the correlation in the risk of death among siblings. The basic argument was that the survival or otherwise of an infant depends on that of his/her immediate predecessor. Alternatively, the death of a previous child is believed to reduce the survival chances of an index child. Although a few previous studies have investigated the effect of the survival of the previous child on infant mortality (Ikamari, 2000; Zenger, 1993), they were however not within the context of clustering; neither did they quantify the extent of sibling mortality correlation net of unobserved heterogeneity. In this study, we attempt to bridge this gap by investigating the infant mortality risk associated with death of a preceding child (sibling mortality correlation) while controlling for unobserved heterogeneity using data from four rounds of demographic and health survey in Nigeria.

\section{Methods}

Data sources

Data for this study were extracted from the birth history records of the 1990, 2003, 2008 and 2013 Nigeria Demographic and Health Survey (NDHS). The NDHS is a 
cross-sectional nationally representative household survey first conducted in 1990 while the most recent was in 2013. Selection of eligible women for interview involved a two-stage stratified cluster sampling technique. Detailed descriptions of the survey methodologies are available in the respective reports (National Population Commission (NPC) [Nigeria], 2014; National Population Commission [Nigeria], 2004).

Out of the five rounds conducted so far $(1990,1999,2003,2008$ and 2013), the greatest decline in childhood mortality was observed between 2003 and 2013 (Akinyemi et al., 2015). Evidence actually shows that several other countries witnessed a faster decline in childhood mortality since 2000s (UNICEF, 2015). To undertake a robust exploration of infant death clustering among different birth cohorts of Nigerian children, birth history data from the four surveys (1990, 2003, 2008 and 2013) were merged together and analysed.

\section{Study sample}

Analysis of the birth history data was restricted to birth cohorts grouped as follows: 1980-1989, 1990-1999, 2000-2009 and 2010 onward. This classification was based on prior evidence on childhood mortality patterns in Nigeria which revealed that the levels were higher in the 1980s and 1990s but gradually declined since early 2000s (Akinyemi et al., 2015). Multiple births were excluded from the analysis because of their higher risk of death in early childhood (Uthman, Uthman, \& Yahaya, 2008). The final weighted sample size was 232,090 births to 56,123 women.

\section{Variables}

The outcome variable analysed in this study was the risk of infant death which refers to death of a child within the first 11 months after birth. We focused on infancy because more than half of deaths among under-five children occur in the first few months after birth (Rajaratnam et al., 2010). In the DHS, birth history data were collected on every child a woman has given birth to. Variables collected include the date of birth, sex, survival status, preceding birth interval and age at death if the child is not alive at the time of the survey.

The primary explanatory variable which was also used to capture sibling mortality correlation was the survival status of the immediate preceding child. Other determinants of infant mortality which are either specific to each child or known to be constant once a woman starts childbearing were included as control variables. The following child characteristics were analysed: sex, birth interval and birth order. Birth interval is a major biological determinant of infant mortality (Rutstein, 2008b) and is important in this study because the death of a preceding child could result in a shorter birth interval for the next. In such circumstance, birth interval may partly explain sibling mortality correlation. Birth order is also important in a high-fertility setting like Nigeria in view of the established knowledge that the risk of infant mortality is higher among multiparous women (Akinyemi et al., 2013).

Maternal factors included in the analysis were the age of the mother at child's birth, maternal education, household wealth index, type of residence, religion and geo-political region. Maternal education is a critical factor in child survival because it is an indicator of the socio-economic status of the mother as well as her knowledge and 
skill in child care (Smith-Greenaway, 2013). Also, previous studies have shown that child mortality rates in Nigeria are higher in rural areas and in the North West and North East regions (Adedini et al., 2014b; Antai, 2011). We also controlled for religious affiliation (Christianity, Islam or traditional) of the mother because it has been shown that certain childcare behaviour and related practices are influenced by religious beliefs (Antai \& Antai, 2008). The household wealth index was derived from ownership of selected items using principal component analysis (Rutstein \& Staveteig, 2014). It was categorised as poorest, poorer, middle, richer and richest. Wealth index has been used as an indicator of socio-economic status in previous studies on maternal and child health (Rutstein, 2008a). Other variables such as maternal and child healthcare utilisation were excluded because they were collected only for the index child in the surveys. The effects of these unobserved variables were appropriately captured in the random component of the fitted models.

\section{Description of the statistical model}

Following methodological developments for infant death clustering and unobserved heterogeneity (Arulampalam \& Bhalotra, 2008; Saha \& van Soest, 2011), we employed a dynamic random effects model to investigate the effect of death of the immediate preceding child (sibling mortality correlation) on infant mortality. Detailed explanations of the advanced statistical models can be found in the above-cited references. However, the basic theoretical underpinnings are briefly described. Issues of empirical and statistical interest are the need to account for sibling mortality correlation, observed maternal/children variables and unobserved heterogeneity due to characteristics shared by children from the same mother/family, household and community. The model equation was as follows:

$$
y_{i, j}^{*}=x_{i j}^{\prime} \beta+\gamma y_{i j-1}+\alpha_{i}+u_{i j}
$$

where $y_{i, j}^{*}$ is the probability of death for infant $j$ from mother $i, x$ represents observed child-level and maternal covariates and $\beta$ is the coefficient (effect) of the covariates. $\gamma$ captured the sibling mortality correlation which is the effect of death of the previous child, $y_{j-1}, \alpha_{i}$ is a random parameter representing the unobserved heterogeneity (at family, household and community levels) while the last component, $u_{i j}$, is the error term which assumed a normal distribution with a mean of zero and variance, $\sigma_{u}^{2}$. Hypothesis was tested for $\alpha=0$ which implied that unobserved heterogeneity has no effect on the probability of infant death. Similarly, hypothesis $\gamma=0$ means that there was no sibling mortality correlation or that death of the preceding child does not affect the risk of infant death in the index child.

The expression in Eq. (1) is a form of a Markov chain model because of the assumption that the death of a child depends on that of its predecessor (Omariba et al., 2008). In this study, a first-order Markov chain model was implemented which means that the death of a child is only dependent on that of its immediate predecessor.

Inclusion of the term $y_{i j-1}$ in the model imposed a constraint because the term $\left(y_{i j-1}\right)$ was non-existent for firstborn children since they have no predecessors. In the econometrics literature where the model originated, this is known as the "initial condition problem". Further explanations on this and different approaches to deal with it are provided in 
Arulampalam et al. (2006). During modelling, this constraint was handled by specifying a separate equation for first births. The equation is as follows:

$$
y_{i 1}^{*}=z^{\prime} \lambda+\theta \alpha_{i}+u_{i 1} \quad i=1, \ldots \ldots n
$$

where $z$ is a factor of covariates related to the survival of first births with $\lambda$ representing their coefficient. The effect of unmeasured variables (unobserved heterogeneity) was represented by $\theta \alpha_{i}$ in Eq. (2) above. Equations (1) and (2) therefore represent a complete model for infant mortality with due control for sibling mortality correlation (death of preceding child), observed maternal and child variables and unobserved heterogeneity.

The final joint dynamic random effects model was fitted using a Stata programme called redprob (Stewart, 2006). The programme produced estimates for sibling mortality correlation, effect of covariates $(x)$, variance due to unobserved heterogeneity and their standard errors. It was implemented in Stata MP version 14.

\section{Analysis}

The first stage of data analysis involved the use of descriptive statistical tools to summarise the explanatory variables according to child birth cohorts. This afforded the opportunity to assess variations in the maternal and other background characteristics of children in the four birth cohorts. Furthermore, to provide a clear indication of child death clustering among women, we described the distribution of infant deaths among the 56,123 mothers according to maternal cohort.

The probability of infant death was estimated using life table techniques as applied in previous studies (Akinyemi, Adedini, Wandera, \& Odimegwu, 2016). Similar to previous studies (Arulampalam \& Bhalotra, 2008; Saha \& van Soest, 2011), the probability of infant death was estimated conditional on death of the immediate preceding child $\left(p_{1}\right)$ and conditional on the survival of the immediate preceding child $\left(p_{0}\right)$. The two probabilities were subsequently used to derive the average partial effect (APE) of sibling mortality concentration. APE was estimated as $p_{1}-p_{0}$, and this gives an indication of the excess probability of infant death attributable to death of the preceding child. This measure was first estimated based on raw data and therefore not adjusted for background variables, correlated mortality risk and unobserved heterogeneity. Later in the analysis, after the dynamic random effects models were fitted, the same measures were re-estimated and adjusted by using parameters obtained from the models. Separate models were fitted for the four child birth cohorts to describe changes in sibling mortality correlation over time. We estimated the percentage of infant death explained by sibling mortality correlation. This was calculated as the ratio of the adjusted APE to the unadjusted APE.

To further explore how sibling mortality correlation affects infant mortality, four multivariable models were fitted to the pooled birth history data in a sequential manner. Model I included only the survival status of the preceding child. For model II, we included child birth cohort as dummy variables along with an interaction term for the survival status of the preceding child and child birth cohort. Model I assessed the overall influence of sibling mortality correlation on infant death, while the interaction term in model II was used to investigate the temporal trends in the effect of death of the preceding child (sibling mortality correlation). Coefficients for dummy-coded child 
birth cohort are indicative of trend in infant mortality risk (which is not the focus in this paper), while the interaction term was used to assess changes in sibling mortality correlation over time. A statistically significant interaction term implies that sibling mortality correlation has changed.

In model III, all other background characteristics except birth interval were added to model II to investigate the extent to which these factors explain the effect of sibling mortality correlation on infant mortality. Lastly, birth interval was added in model IV to explore its role as potential pathway through which sibling mortality correlation affects infant death.

\section{Ethical approval}

Data analysed in this study were retrieved from the DHS online archive after due approval. Besides, NDHS 2008 and 2013 were approved by the Nigeria National Health Research Ethics Committee. DHS questionnaires and protocols were reviewed and approved by the ICF Institutional Review Board (The DHS Program, 2017) to ensure compliance with the U.S. Department of Health and Human Services regulations for the protection of human subjects (45 CFR 46).

\section{Results}

\section{Background characteristics}

Background characteristics of births to women are presented in Table 1 according to birth cohorts. The percentage of male births ranged from 52.3\% in the 1980-1989 birth cohorts to $50.4 \%$ among the cohorts born in 2010 onward. The proportion of first births decreased gradually from $32.8 \%$ in the $1980-1989$ birth cohort to $19.9 \%$ in the most recent cohort, but a reverse pattern was observed for births of order 6 and above. With respect to birth interval, the percentage of children born within 24 months after a preceding birth declined from 27.1\% (1980-1989 birth cohort) to $17.1 \%$ ( $\geq 2010$ birth cohort) while the percentage born after at least 36 months had increased from 11.7 to $29.9 \%$.

Furthermore, there has been a gradual change in the age distribution of childbearing. Among the 1980-1989 birth cohorts, 37.9\% of their mothers were aged below 20 years compared to $12.6 \%$ in the $2010+$ cohort. Notable shift was also observed in maternal education such that the percentage of births to women with secondary/higher education rose from 15.3 to $32.5 \%$. Rural-urban distribution remained almost the same with about two thirds of children in every birth cohort being born to women in rural areas.

\section{Infant death clustering}

Descriptive findings on infant death clustering among the 56,123 mothers are presented in Table 2 according to maternal birth cohorts. The percentage of women with no experience of infant death rose from $67.1 \%$ among the oldest cohort (born $\leq 1969$ ) to $83.4 \%$ in the youngest cohort of mothers (born $\geq 1980$ ). As an indication of infant death concentration among women, $13.2 \%$ of women in the oldest cohort $(\leq 1969)$ have experienced death of at least two infants and these accounted for $40.2 \%$ of all infant deaths. Among the 1970-1979 maternal cohort, 8.6\% had experienced multiple infant deaths and accounted for $31.6 \%$ of women whose infants had died. In the youngest maternal 
Table 1 Background characteristics of births, Nigeria, 1980-2013

\begin{tabular}{|c|c|c|c|c|}
\hline \multirow[t]{2}{*}{ Variables } & \multicolumn{4}{|l|}{ Birth cohorts } \\
\hline & $\begin{array}{l}1980-1989 \\
(n=30,330)\end{array}$ & $\begin{array}{l}1990-1999 \\
(n=74,211)\end{array}$ & $\begin{array}{l}2000-2009 \\
(n=106,478)\end{array}$ & $\begin{array}{l}\geq 2010 \\
(n=21,071)\end{array}$ \\
\hline \multicolumn{5}{|l|}{ Child-related variables } \\
\hline Male sex & 52.3 & 51.3 & 51.0 & 50.4 \\
\hline \multicolumn{5}{|l|}{ Birth order } \\
\hline 1 & 32.8 & 23.7 & 20.3 & 19.9 \\
\hline $2-3$ & 41.7 & 36.0 & 33.6 & 32.4 \\
\hline $4-5$ & 18.2 & 22.2 & 23.2 & 23.1 \\
\hline $6+$ & 7.4 & 18.1 & 22.9 & 24.7 \\
\hline \multicolumn{5}{|l|}{ Birth interval } \\
\hline First born & 32.8 & 23.7 & 20.3 & 19.9 \\
\hline$<24$ & 27.1 & 26.1 & 23.8 & 17.1 \\
\hline $24-36$ & 28.5 & 30.5 & 31.9 & 33.2 \\
\hline$>36$ & 11.7 & 19.6 & 24.0 & 29.9 \\
\hline \multicolumn{5}{|l|}{ Maternal variables } \\
\hline \multicolumn{5}{|l|}{ Age at child's birth } \\
\hline$<20$ & 37.9 & 21.4 & 16.0 & 12.6 \\
\hline $20-34$ & 61.9 & 73.5 & 69.5 & 70.3 \\
\hline$\geq 35$ & 0.2 & 5.1 & 14.5 & 17.1 \\
\hline \multicolumn{5}{|l|}{ Education } \\
\hline None & 59.9 & 54.5 & 51.4 & 48.9 \\
\hline Primary & 24.8 & 24.7 & 22.5 & 18.6 \\
\hline Secondary/higher & 15.3 & 20.8 & 26.0 & 32.5 \\
\hline \multicolumn{5}{|c|}{ Household wealth quintile } \\
\hline Poorest & 24.4 & 25.0 & 24.9 & 23.4 \\
\hline Poorer & 22.4 & 22.8 & 23.2 & 23.3 \\
\hline Middle & 21.0 & 20.3 & 19.1 & 18.9 \\
\hline Richer & 18.4 & 17.6 & 17.3 & 17.7 \\
\hline Richest & 13.8 & 14.4 & 15.5 & 16.7 \\
\hline \multicolumn{5}{|l|}{ Religion } \\
\hline Christianity & 39.3 & 38.2 & 37.3 & 36.4 \\
\hline Islam & 46.3 & 51.0 & 58.1 & 62.1 \\
\hline Others & 14.4 & 10.8 & 4.6 & 1.5 \\
\hline \multicolumn{5}{|c|}{ Type of place of residence } \\
\hline Rural & 31.1 & 30.8 & 31.4 & 34.6 \\
\hline Urban & 68.8 & 69.2 & 68.6 & 65.4 \\
\hline \multicolumn{5}{|l|}{ Region } \\
\hline North Central & 16.6 & 17.5 & 17.5 & 17.3 \\
\hline North East & 34.5 & 35.1 & 35.9 & 37.5 \\
\hline North West & 12.0 & 13.2 & 13.6 & 13.7 \\
\hline South East & 10.4 & 9.4 & 8.6 & 8.9 \\
\hline South South & 14.4 & 11.7 & 10.7 & 9.4 \\
\hline South West & 12.0 & 13.1 & 13.8 & 13.2 \\
\hline
\end{tabular}


Table 2 Infant death clustering among three maternal cohorts in Nigeria, 1980-2013

\begin{tabular}{|c|c|c|c|c|c|c|}
\hline \multirow{3}{*}{$\begin{array}{l}\text { No. of } \\
\text { infant } \\
\text { deaths }\end{array}$} & \multicolumn{6}{|c|}{ Maternal cohorts } \\
\hline & \multicolumn{2}{|l|}{$\leq 1969$} & \multicolumn{2}{|l|}{ 1970-1979 } & \multicolumn{2}{|l|}{$\geq 1980$} \\
\hline & $\begin{array}{l}\text { All } \\
\text { women (\%) }\end{array}$ & $\begin{array}{l}\text { Women with } \\
\text { infant deaths (\%) }\end{array}$ & $\begin{array}{l}\text { All } \\
\text { women (\%) }\end{array}$ & $\begin{array}{l}\text { Women with } \\
\text { infant deaths (\%) }\end{array}$ & $\begin{array}{l}\text { All } \\
\text { women (\%) }\end{array}$ & $\begin{array}{l}\text { Women with } \\
\text { infant deaths (\%) }\end{array}$ \\
\hline 0 & 67.1 & & 72.9 & & 83.4 & \\
\hline 1 & 19.7 & 59.8 & 18.5 & 68.4 & 13.3 & 79.7 \\
\hline 2 & 8.1 & 24.5 & 5.7 & 21.1 & 2.7 & 16.2 \\
\hline 3 & 3.1 & 9.5 & 1.8 & 6.7 & 0.5 & 3.0 \\
\hline 4 & 1.4 & 4.3 & 0.7 & 2.4 & 0.1 & 0.8 \\
\hline $5+$ & 0.6 & 1.9 & 0.4 & 1.4 & 0.0 & 0.3 \\
\hline Number & 12,529 & 4124 & 18,495 & 5008 & 25,099 & 4172 \\
\hline
\end{tabular}

cohort ( $\geq 1980$ ), 3.3\% had recorded multiple infant deaths but accounted for $20.3 \%$ of all women who had lost infants to death. Overall, there was a notable decline in infant death concentration from the oldest to youngest maternal cohorts.

Figure 1 shows the distribution of infant death clustering across the six geo-political regions in Nigeria. Though death clustering was most prevalent in North East, North West and North Central, it was common in all the other three regions (South East, South South and South West). In addition, the graph also showed that the level of infant death clustering declined over time in all regions.

Table 3 provides further measures on the contribution of death clustering to infant mortality. To profile the temporal pattern from 1980s till 2010s, results were presented according to child birth cohort. The average partial effect (APE) which represents the excess probability of infant death given that the immediate preceding child also died in infancy declined from 0.17 in 1980-1989 to 0.08 in 2010 onward.

Parameter estimates from the full dynamic random effects model were also used to generate adjusted APE (Table 4). The results show that after adjusting for selected observed variables and unobserved heterogeneity, sibling mortality correlation increased the probability of infant death by 0.080 and 0.061 in the $1980-1989$ and 2010 birth

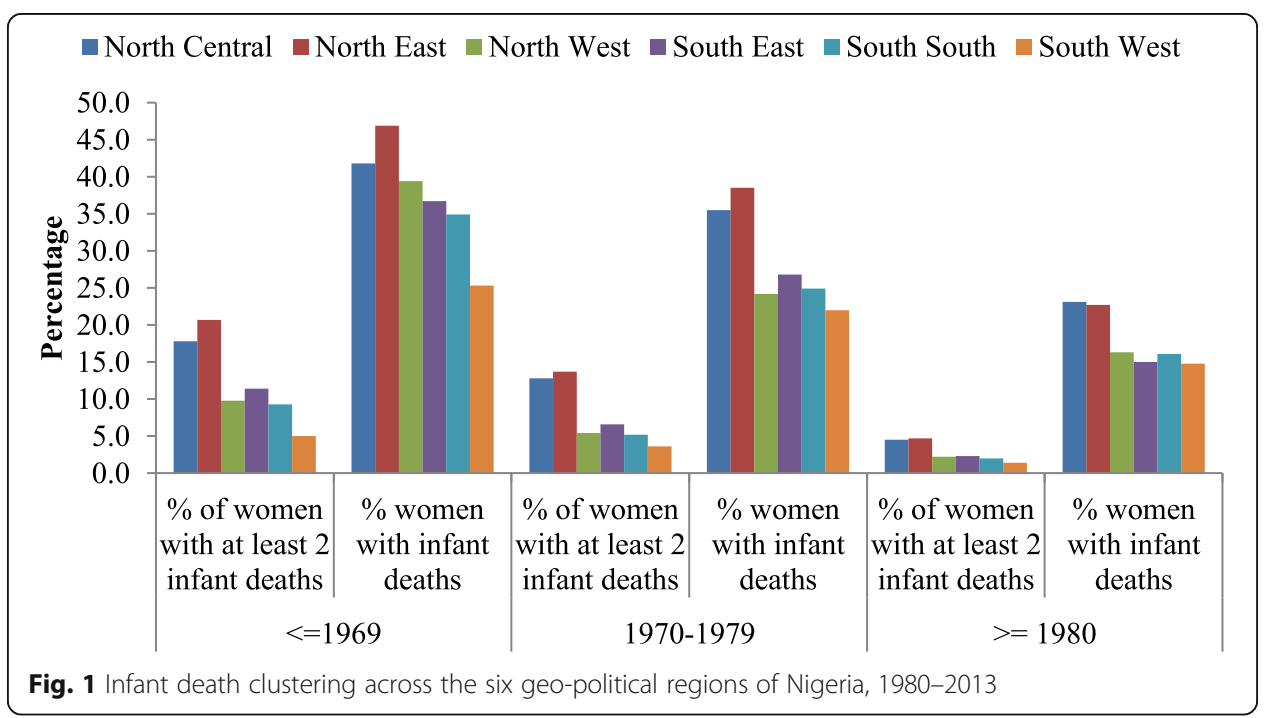


Table 3 Unadjusted average partial effect of sibling mortality correlation on probability of infant death in Nigeria, 1980-2013

\begin{tabular}{|c|c|c|c|c|c|c|}
\hline $\begin{array}{l}\text { Row } \\
\text { no. }\end{array}$ & Probabilities & Computation & $\begin{array}{l}1980- \\
1989 \\
(n= \\
30,330)\end{array}$ & $\begin{array}{l}1990- \\
1999 \\
(n= \\
74,211)\end{array}$ & $\begin{array}{l}2000- \\
2009 \\
(106478)\end{array}$ & $\begin{array}{l}\geq 2010 \\
(n= \\
21,071)\end{array}$ \\
\hline 1 & $\begin{array}{l}\text { Probability of infant death } \\
\text { conditional on death of the } \\
\text { preceding sibling }\left(p_{1}\right)\end{array}$ & $\begin{array}{l}\text { Obtained from the life table } \\
\text { technique using the Kaplan- } \\
\text { Meier method }\end{array}$ & 0.2435 & 0.247 & 0.1982 & 0.1262 \\
\hline 2 & $\begin{array}{l}\text { Probability of infant death } \\
\text { conditional on survival of the } \\
\text { preceding sibling }\left(p_{0}\right)\end{array}$ & $\begin{array}{l}\text { Obtained from the life table } \\
\text { technique using the Kaplan- } \\
\text { Meier method }\end{array}$ & 0.0763 & 0.0752 & 0.0643 & 0.0499 \\
\hline 3 & Average partial effect $\left(p_{1}-p_{0}\right)$ & Row 1 - row 2 & 0.1672 & 0.1718 & 0.1339 & 0.0763 \\
\hline
\end{tabular}

cohorts respectively. In other words, with death of the preceding child, the infant mortality level was higher by 61 deaths per 1000 live births among children in the 2010 birth cohorts. The percentage of infant death explained by sibling mortality correlation ranged from $48.1 \%$ in $1980-1989$ birth cohort to $79.9 \%$ in the $2010-2013$ birth cohort.

Detailed results from models based on full birth history for 1980-2013 are presented in Table 5. The coefficient for death of the preceding child was positive and statistically significant in all four models which showed that the risk of infant death was significantly higher when the immediate preceding child also died during infancy (effect of sibling mortality correlation). In model II, the coefficient of interaction term for death of the preceding child and child birth cohort was negative and statistically significant. This is an indication that the effect of death of the preceding child (sibling mortality correlation) had declined over time.

Changes in the coefficient for death of the preceding child between model II and model III showed that the adjusted variables partly explained the effect of sibling mortality correlation which remained statistically significant. The percentage change in the coefficient of death of the preceding child between model II and model IV was $10 \%$. Both birth interval and death of the preceding child remained statistically significant as determinants of infant death. The effects of other variables such as male sex, birth order, maternal education and age at child's birth maintained their expected direction

Table 4 Adjusted contribution of death clustering to infant mortality in Nigeria, 1980-2013

\begin{tabular}{|c|c|c|c|c|c|c|}
\hline $\begin{array}{l}\text { Row } \\
\text { no. }\end{array}$ & Probabilities & Computation & $\begin{array}{l}1980- \\
1989 \\
(n= \\
30,330)\end{array}$ & $\begin{array}{l}1990- \\
1999 \\
(n= \\
74,211)\end{array}$ & $\begin{array}{l}2000- \\
2009 \\
(n= \\
106,478)\end{array}$ & $\begin{array}{l}\geq 2010 \\
(n= \\
21,071)\end{array}$ \\
\hline 1 & $\begin{array}{l}\text { Predicted probability of infant } \\
\text { death conditional on death of } \\
\text { the preceding sibling excluding } \\
\text { the first births }\left(p_{1}\right)\end{array}$ & $\begin{array}{l}\text { Conditional on the death of the } \\
\text { preceding sibling; this was } \\
\text { obtained from the probabilities } \\
\text { predicted using model } \\
\text { parameters }\end{array}$ & 0.1658 & 0.166 & 0.1406 & 0.0929 \\
\hline 2 & $\begin{array}{l}\text { Predicted probability of infant } \\
\text { death conditional on survival of } \\
\text { the preceding sibling excluding } \\
\text { the first births }\left(p_{0}\right)\end{array}$ & $\begin{array}{l}\text { Conditional on the survival of } \\
\text { the preceding sibling; this was } \\
\text { obtained from the probabilities } \\
\text { predicted using model } \\
\text { parameters }\end{array}$ & 0.0854 & 0.0849 & 0.0664 & 0.0319 \\
\hline 3 & $\begin{array}{l}\text { Adjusted APE [excluding first } \\
\text { births] }\left(p_{1}-p_{0}\right)\end{array}$ & Row 2 - row 1 & 0.0804 & 0.0811 & 0.0742 & 0.061 \\
\hline 4 & $\begin{array}{l}\% \text { infant death explained by } \\
\text { clustering }\end{array}$ & (Row 3/row 3 Table 3) × 100 & 48.1 & 47.2 & 55.4 & 79.9 \\
\hline
\end{tabular}


Table 5 Results from dynamic random effects models for infant mortality, Nigeria, 1980-2013

\begin{tabular}{|c|c|c|c|c|}
\hline & \multicolumn{4}{|c|}{ Coefficients (standard error) } \\
\hline & Model I & Model II & Model III & Model IV \\
\hline \multicolumn{5}{|l|}{ Child-related variables } \\
\hline Death of preceding child, $\gamma$ (SE) & $\begin{array}{l}0.4859 \\
(0.0159)^{*}\end{array}$ & $\begin{array}{l}0.7069 \\
(0.0423)^{*}\end{array}$ & $\begin{array}{l}0.6773 \\
(0.0423)^{*}\end{array}$ & $\begin{array}{l}0.6318 \\
(0.0426)^{*}\end{array}$ \\
\hline \multicolumn{5}{|l|}{ Child birth cohort } \\
\hline \multicolumn{5}{|l|}{ 1980-1989 (ref) } \\
\hline 1990-1999 & & $\begin{array}{l}0.0214 \\
(0.0166)\end{array}$ & $\begin{array}{l}0.00913 \\
(0.0183)\end{array}$ & $\begin{array}{l}0.0513 \\
(0.0185)^{*}\end{array}$ \\
\hline 2000-2009 & & $\begin{array}{l}-0.0664 \\
(0.0170)^{*}\end{array}$ & $\begin{array}{l}-0.0903 \\
(0.0233)^{*}\end{array}$ & $\begin{array}{l}-0.0135 \\
(0.0236)\end{array}$ \\
\hline$\geq 2010$ & & $\begin{array}{l}-0.2342 \\
(0.0239)^{*}\end{array}$ & $\begin{array}{l}-0.2538 \\
(0.0319)^{*}\end{array}$ & $\begin{array}{l}-0.1235 \\
(0.0324)^{*}\end{array}$ \\
\hline \multicolumn{5}{|l|}{ Interaction term } \\
\hline $\begin{array}{l}\text { Death of preceding child } \times \text { child birth } \\
\text { cohort }\end{array}$ & & $\begin{array}{l}-0.0932 \\
(0.0163)^{*}\end{array}$ & $\begin{array}{l}-0.0886 \\
(0.0163)^{*}\end{array}$ & $\begin{array}{l}-0.0999 \\
(0.0164)^{*}\end{array}$ \\
\hline Male sex & & & $\begin{array}{l}0.0832 \\
(0.0094)^{*}\end{array}$ & $\begin{array}{l}0.0832 \\
(0.0095)^{*}\end{array}$ \\
\hline \multicolumn{5}{|l|}{ Birth order } \\
\hline \multicolumn{5}{|l|}{1 (ref) } \\
\hline $2-3$ & & & $\begin{array}{l}-0.1846 \\
(0.0146)^{*}\end{array}$ & $\begin{array}{l}-0.1329 \\
(0.0148)^{*}\end{array}$ \\
\hline $4-5$ & & & $\begin{array}{l}-0.0979 \\
(0.0134)^{*}\end{array}$ & $\begin{array}{l}-0.0729 \\
(0.0136)^{*}\end{array}$ \\
\hline \multicolumn{5}{|l|}{$6+$} \\
\hline \multicolumn{5}{|l|}{ Birth interval } \\
\hline$<24$ & & & & $\begin{array}{l}0.4681 \\
(0.0137)^{*}\end{array}$ \\
\hline $24-36$ & & & & $\begin{array}{l}0.2434 \\
(0.0133)^{*}\end{array}$ \\
\hline$>36$ (ref) & & & & \\
\hline
\end{tabular}

Maternal variables

Age at child's birth

$<20$ (ref)

20-34

$\begin{array}{ll}-0.1836 & -0.1267\end{array}$

$(0.0169)^{*} \quad(0.0170)^{*}$

$\geq 35$

$-0.0582$

Education

None (ref)

Primary

$\begin{array}{ll}-0.0323 & -0.0299\end{array}$

$(0.0149)^{*} \quad(0.0149)^{*}$

Secondary/higher

$-0.0516 \quad-0.0526$

$(0.0189)^{*} \quad(0.0191)^{*}$

Household wealth quintile

Poorest (ref)

Poorer

$\begin{array}{ll}-0.0021 & -0.0043\end{array}$

$(0.0138)^{*} \quad(0.0139)^{*}$

Middle

$-0.1226 \quad-0.1201$

$(0.0162)^{*} \quad(0.0164)^{*}$

Richer

$-0.1459 \quad-0.1420$ 
Table 5 Results from dynamic random effects models for infant mortality, Nigeria, 1980-2013 (Continued)

\begin{tabular}{|c|c|c|c|c|}
\hline & Coefficients ( & andard error) & & \\
\hline & Model I & Model II & Model III & Model IV \\
\hline & & & $(0.0194)^{*}$ & $(0.0195)^{*}$ \\
\hline Richest & & & $\begin{array}{l}-0.2122 \\
(0.0253)^{*}\end{array}$ & $\begin{array}{l}-0.2129 \\
(0.0255)^{*}\end{array}$ \\
\hline Religion & & & & \\
\hline Christianity & & & $\begin{array}{l}-0.0589 \\
(0.0219)^{*}\end{array}$ & $\begin{array}{l}-0.0657 \\
(0.0221)^{*}\end{array}$ \\
\hline Islam & & & $\begin{array}{l}-0.0728 \\
(0.0192)^{*}\end{array}$ & $\begin{array}{l}-0.0866 \\
(0.0194)^{*}\end{array}$ \\
\hline Others (ref) & & & & \\
\hline Type of place of residence & & & & \\
\hline Rural & & & $\begin{array}{l}0.0339 \\
(0.0141)^{*}\end{array}$ & $\begin{array}{l}0.0329 \\
(0.0142)^{*}\end{array}$ \\
\hline Urban (ref) & & & & \\
\hline Region & & & & \\
\hline North Central & & & $\begin{array}{l}-0.0358 \\
(0.0226)\end{array}$ & $\begin{array}{l}-0.0529 \\
(0.0229)^{*}\end{array}$ \\
\hline North East & & & $\begin{array}{l}0.0644 \\
(0.0266)^{*}\end{array}$ & $\begin{array}{l}0.0269 \\
(0.0229)\end{array}$ \\
\hline North West & & & $\begin{array}{l}0.0792 \\
(0.0225)^{*}\end{array}$ & $\begin{array}{l}0.0456 \\
(0.0228)^{*}\end{array}$ \\
\hline South East & & & $\begin{array}{l}0.1067 \\
(0.0247)^{*}\end{array}$ & $\begin{array}{l}0.0573 \\
(0.0249)^{*}\end{array}$ \\
\hline South South & & & $\begin{array}{l}0.0297 \\
(0.0240)^{*}\end{array}$ & $\begin{array}{l}0.0052 \\
(0.0242)\end{array}$ \\
\hline South West (ref) & & & & \\
\hline Other model parameters & & & & \\
\hline$\theta(\mathrm{SE})$ & $\begin{array}{l}0.8939 \\
(0.0708)^{*}\end{array}$ & $\begin{array}{l}0.8691 \\
(0.0698)^{*}\end{array}$ & $\begin{array}{l}0.9169 \\
(0.0807)^{*}\end{array}$ & $\begin{array}{l}0.9133 \\
(0.0807)^{*}\end{array}$ \\
\hline Family-level heterogeneity (SE) & $\begin{array}{l}0.1246 \\
(0.0065)^{*}\end{array}$ & $\begin{array}{l}0.1257 \\
(0.0067)^{*}\end{array}$ & $\begin{array}{l}0.1116 \\
(0.0068)^{*}\end{array}$ & $\begin{array}{l}0.1126 \\
(0.0069)^{*}\end{array}$ \\
\hline Log-likelihood & $-64,816.322$ & $-64,666.778$ & $-64,145.23$ & $-63,508.255$ \\
\hline
\end{tabular}

which is well known in the literature. The results for unobserved heterogeneity also retained their statistical significance in all the models.

\section{Discussion}

Infant death clustering or concentration of infant death in certain women has the potential to slow down the desired progress in child survival. Although not a new phenomenon, methodological advancement has made it possible to clearly demonstrate that infant death clustering is different from unobserved heterogeneity. Apart from monitoring the reduction of childhood mortality levels, it is also necessary to pay attention to death clustering. Using birth history data from four DHSs in Nigeria, this study was conducted to contribute evidence in this regard.

Infant death clustering was found to be prevalent in Nigeria. The degree of child death clustering found in this study is higher than observed in other countries such as Kenya (Omariba et al., 2008), Bangladesh (Saha \& van Soest, 2011) and India 
(Arulampalam \& Bhalotra, 2008). This is not surprising given the fact that both fertility and child mortality levels in Nigeria are higher than these countries. Since there is evidence that childhood mortality levels are higher in countries with higher fertility (Silva, 2012), the same pattern may have been mirrored in the level of infant death clustering. Furthermore, results for different maternal cohorts suggest that the general level of infant death clustering in Nigeria has declined over time. This pattern is consistent with prior evidence across several countries in SSA which showed that childhood death clustering reduced with mortality levels (Kuate-Defo \& Diallo, 2002). Further exploration of infant death clustering patterns revealed that though the magnitudes differ, the phenomenon is present across the six geo-political regions. This agrees with a previous study which showed that determinants of childhood mortality are virtually the same across the different regions in Nigeria (Akinyemi et al., 2015).

The results confirmed that death clustering (as indicated by sibling mortality correlation) is a major contributor to overall levels of infant mortality. In fact, the percentage of infant death explained by clustering in Nigeria was found greater than that obtained in Kenya (40\%) and India (15\%). Besides, in conformity with the existing literature (Arulampalam \& Bhalotra, 2008; Saha \& van Soest, 2011), the effect of sibling mortality correlation remained statistically significant even after observed and unobserved variables (heterogeneity) have been controlled. Although birth interval partly explained the effect of sibling mortality correlation, however, both factors remained statistically significant in the full model. Death of an immediate preceding child could shorten the length of postpartum amenorrhea due to cessation of breastfeeding, thereby making a woman become pregnant within a shorter interval. This explanation was termed "fecundity hypothesis" by Arulampalam et al. (Arulampalam \& Bhalotra, 2006). Death of the preceding child could also trigger what is known as the replacement effect (Rutstein \& Winter, 2014) which implied that a woman intentionally makes effort to replace a dead child notwithstanding the prevailing circumstances that led to his/her death. Exploration of the replacement effect will require detailed analysis of contraceptive use history in the inter-birth periods. Unfortunately, such data are not available in the Nigeria DHS.

Although sibling mortality correlation was found to have decreased over time, its contribution to infant death rose from 55.4\% in the 2000-2009 child cohort to $79.9 \%$ in the most recent cohort (2010). This shows a distinction between the magnitude and impact of death clustering on infant mortality levels. A substantial impact of sibling mortality correlation as found in this study is a re-awakening on the urgent need to prevent infant death to forestall the risk it constitutes for the survival of succeeding births. It also underscores how infant death clustering could be triggered by the death of a child. In addition, increased impact of sibling mortality correlation may also be related to the poor state of maternal and child healthcare utilisation in the country (Winter et al., 2016). Death clustering was almost non-existent in a rural area of Bangladesh where health service coverage was optimal (Saha \& van Soest, 2011). Investigation of the maternal and child healthcare continuum in Nigeria revealed that the level of dropout at different stages is very high (Akinyemi, Afolabi, \& Awolude, 2016). This can no doubt contribute to the persistence of infant death clustering.

A significant net effect of sibling mortality correlation after adjustment for birth interval, background socio-demographic characteristics and unobserved heterogeneity 
implied that apart from the fecundity hypothesis, other processes or factors may be involved. Child healthcare practices, environmental and heredity cannot be ruled out. Recent empirical evidence on the causes of childhood deaths in Nigeria showed that sepsis, birth injury and pneumonia are prevalent (Adewemimo et al., 2017). Incidentally, data from the NDHS also revealed that coverage of medical treatment for fever and symptoms of acute respiratory tract infections remained stagnated at low levels between 2003 and 2013 (Winter et al., 2016). Without sustained improvement in maternal and child healthcare utilisation, infant death clustering might remain high and eventually slow down the progress desired for child survival.

An obvious limitation in this study stems from the fact that there was no data to permit exploration of other possible explanations for sibling mortality correlation. Such unobserved factors include maternal knowledge and competence in child care, cultural and environmental factors and other biological/genetic factors. Although our analytical method aptly captured these as unobserved heterogeneity, proper identification of the effects of these factors in child health and survival would need further research. Also, some variables such as maternal and childcare utilisation were not controlled in the analysis. These variables were not captured in the cross-sectional DHS birth histories. Although analysis could have been restricted to 5-year birth history so that some of these variables can be included in the models, this would have made it difficult to properly explore the temporal pattern in death clustering because the data would have covered only 5 years.

Another source of limitation is the non-availability of time-varying covariates in the DHS data. For example, mothers might have migrated from rural to urban areas during the course of child bearing. Change in place of residence poses different risks to child survival. Also, children born to a woman might have different fathers as union instability and remarriage is common (Isiugo-Abanihe, 1998). Many of these time-varying characteristics could not be adjusted. Rather, they were captured as unobserved heterogeneity for the purpose of statistical efficiency.

\section{Conclusion}

There is a substantial level of infant death clustering in Nigeria. Analysis of birth history data within a space of about three decades (1980-2013) revealed that there has been a little decline over time. Mortality risks shared by infants born to the same mother are a major contributor to death clustering and overall levels of infant mortality. These results have important implications for research, policies and programmes. Beyond the known determinants of childhood mortality, further research needs to unravel the unknown factors driving death concentration in certain women. By implication, it has become imperative to understand the steps or actions taken by parents and especially women to prevent repeated child deaths. To unravel these, longitudinal studies using a mix of data collection methodologies would be necessary.

A slow decline of infant death clustering throws up a new challenge to child survival programmes. If death clustering should remain stagnated, it means that inequity in child health and survival will persist and a stage would be reached that further decline in childhood mortality becomes difficult. This definitely negates the current sustainable development goal whose overarching intention is to "live no 
one behind" (WHO, 2015). It is therefore important to continue to prevent child deaths and if a woman ever experiences a child loss, repeat occurrence should be prevented. Advocacy programmes could sensitise the population on the need for extra efforts to ensure that women with experience of infant death be supported to avoid a recurrence. Adequate coverage and uptake of maternal and child healthcare services is a potential strategy in this regard.

\section{Abbreviations}

APE: Average Partial Effect; HDSS: Health and Demographic Surveillance System; NDHS: Nigeria Demographic and Health Survey; NPC: National Population Commission, Nigeria

\section{Acknowledgements}

We appreciate the DHS program and National Population Commission in Nigeria for granting access to the Nigeria DHS data. A version of this paper was presented at the 2017 International Population Conference in Capetown, South Africa.

\section{Funding}

This research was supported by the Consortium for Advanced Research Training in Africa (CARTA). CARTA is jointly led by the African Population and Health Research Center and the University of the Witwatersrand and funded by the Wellcome Trust (UK) (Grant No: 087547/Z/08/Z), the Carnegie Corporation of New York (Grant No--B 8606.R02), Sida (Grant No:54100029) The statements made and views expressed are solely the responsibility of the authors. The funders did not play any role in the design of the study, retrieval, analysis, and interpretation of data and in writing the manuscript.

\section{Availability of data and materials}

The dataset(s) supporting the conclusions of this article is(are) available in the online DHS archive [https://dhsprogram. com/data/available-datasets.cfm]. Permission from the DHS program is required to access the data.

\section{Authors' contributions}

JOA contributed to the conceptualisation and study design, analysis and interpretation and drafting of the manuscript. $\mathrm{COO}, \mathrm{OOB}$ and $\mathrm{BMG}$ contributed to the interpretation of results and revision of intellectual content. All authors read and approved the final manuscript.

\section{Competing interests}

The authors declare that they have no competing interests.

\section{Publisher's Note}

Springer Nature remains neutral with regard to jurisdictional claims in published maps and institutional affiliations.

\section{Author details}

'Demography and Population Studies Programme, Schools of Public Health and Social Sciences, University of the Witwatersrand, Johannesburg, South Africa. ${ }^{2}$ Department of Epidemiology and Medical Statistics, Faculty of Public Health, College of Medicine, University of Ibadan, Ibadan, Nigeria. ${ }^{3}$ Department of Demography and Social Statistics, Faculty of Social Sciences, Obafemi Awolowo University, lle-lfe, Nigeria.

Received: 21 November 2017 Accepted: 12 March 2019

Published online: 03 April 2019

\section{References}

Adedini, S. A., Odimegwu, C., Imasiku, E. N., \& Ononokpono, D. N. (2014a). Ethnic differentials in under-five mortality in Nigeria. Ethnicity and Health, 20(2), 145-162. https://doi.org/10.1080/13557858.2014.890599.

Adedini, S. A., Odimegwu, C., Imasiku, E. N., Ononokpono, D. N., \& Ibisomi, L. (2014b). Regional variations in infant and child mortality in Nigeria: A multilevel analysis. Journal of Biosocial Science, 47(2), 165-187. https://doi.org/10.1017/ s0021932013000734.

Adewemimo, A., Kalter, H. D., Perin, J., Koffi, A. K., Quinley, J., \& Black, R. E. (2017). Direct estimates of cause-specific mortality fractions and rates of under-five deaths in the northern and southern regions of Nigeria by verbal autopsy interview. PLoS One, 12(5), e0178129. https://doi.org/10.1371/journal.pone.0178129.

Adjuik, M., Kanyomse, E., Kondayire, F., Wak, G., \& Hodgson, A. (2010). Clustering of under-five mortality in the Navrongo HDSS in the Kassena-Nankana District of northern Ghana. Global Health Action, 3. https://doi.org/10.3402/gha.v3i0.5233.

Arulampalam, W., and Bhalotra, S. (2006). Sibling Death Clustering in India: State Dependence versus Unobserved Heterogeneity. Journal of the Royal Statistical Society. Series A (Statistics in Society) 169(4), 829-848

Akinyemi, J. O., Adebowale, A. S., Bamgboye, E. A., \& Ayeni, O. (2015). Child survival dynamics in Nigeria: Is the 2006 child health policy target met? Nigerian Journal of Health Sciences, 15(1), 18-26.

Akinyemi, J. O., Adedini, S. A., Wandera, S. O., \& Odimegwu, C. O. (2016). Independent and combined effects of maternal smoking and solid fuel on infant and child mortality in sub-Saharan Africa. Tropical Medicine and International Health, 21(12), 1572-1582. https://doi.org/10.1111/tmi.12779. 
Akinyemi, J. O., Afolabi, R. F., \& Awolude, O. A. (2016). Patterns and determinants of dropout from maternity care continuum in Nigeria. BMC Pregnancy and Childbirth, 16(1), 282. https://doi.org/10.1186/s12884-016-1083-9.

Akinyemi, J. O., Bamgboye, E. A., \& Ayeni, O. (2013). New trends in under-five mortality determinants and their effects on child survival in Nigeria: A review of childhood mortality data from 1990-2008. African Population Studies, 27(1), 25-42 https://doi.org/10.11564/27-1-5.

Alabi, O., Baloye, D., Doctor, H. V., \& Oyedokun, O. A. (2016). Spatial analysis of under-five mortality clustering in northern Nigeria: Findings from Nahuche Health and Demographic Surveillance System, Zamfara State. International Journal of Tropical Disease \& Health, 15(1), 1-10. https://doi.org/10.9734/IJTDH/2016/24709.

Alabi, O., Oyedokun, O. A., Doctor, H. V., \& Adedini, S. A. (2017). Determinants of under-five mortality clustering in a health and demographic surveillance system in Zamfara State, northern Nigeria. African Population Studies, 31 (1 Supp), 3344-3355.

Alkema, L., Kantorova, V., Menozzi, C., \& Biddlecom, A. (2013). National, regional, and global rates and trends in contraceptive prevalence and unmet need for family planning between 1990 and 2015: A systematic and comprehensive analysis. Lancet, 381, 1642-1652. https://doi.org/10.1016/S0140-6736(12)62204-1.

Antai, D. (2011). Regional inequalities in under-5 mortality in Nigeria: A population-based analysis of individual- and community-level determinants. Population Health Metrics, 9(1), 6. https://doi.org/10.1186/1478-7954-9-6.

Antai, D., \& Antai, J. (2008). Individual- and contextual-level determinants of social inequities in under-five mortality in Nigeria: Differentials by religious affiliation of the mother. World Health and Population, 10(4), 38-52.

Antai, D., \& Moradi, T. (2010). Urban area disadvantage and under-5 mortality in Nigeria: The effect of rapid urbanization. Environmental Health Perspectives, 118(6), 877-883.

Arulampalam, W., \& Bhalotra, S. (2006). Sibling death clustering in India: State dependence versus unobserved heterogeneity. Journal of the Royal Statistical Society: Series A (Statistics in Society), 169(4), 829-848.

Arulampalam, W., \& Bhalotra, S. (2008). The linked survival prospects of siblings: Evidence for the Indian states. Population Studies, 62(2), 171-190

Awini, E., Mattah, P., Sankoh, O., \& Gyapong, M. (2010). Spatial variations in childhood mortalities at the Dodowa Health and Demographic Surveillance System site of the INDEPTH Network in Ghana. Tropical Medicine and International Health, 15(5), 520-528. https://doi.org/10.1111/j.1365-3156.2010.02492.x.

Das Gupta, M. (1990). Death clustering, mother's education and determinants of child mortality in rural Punjab, India. Population Studies, 44(3), 489-505.

Edvinsson, S., \& Janssens, A. (2012). Clustering of deaths in families: Infant and child mortality in historical perspective Biodemography and Social Biology, 58(2), 75-86. https://doi.org/10.1080/19485565.2012.738575.

Ikamari, L. (2000). Sibling mortality correlation in Kenya. Journal of Biosocial Science, 32(2), 265-278.

Isiugo-Abanihe, U. C. (1998). Stability of marital unions and fertility in Nigeria. Journal of Biosocial Science, 30(1), 33-41.

Klouda, A. T., \& Adamu, F. (2013). Clustering of child mortality and links to social support in Northern Nigeria. A report submitted to PRRINN-MNCH Programme.

Kuate-Defo, B., \& Diallo, K. (2002). Geography of child mortality clustering within African families. Health \& Place, 8, 93-117.

Lutambi, A. M., Alexander, M., Charles, J., Mahutanga, C., \& Nathan, R. (2010). Under-five mortality: Spatial_temporal clusters in Ifakara HDSS in South-eastern Tanzania. Global Health Action, 3. https://doi.org/10.3402/gha.v3i0.5254.

Madise, N. J., Mathews, Z., \& Whitworth, A. (2014). A tale of two continents: Infant death clustering in India and sub-Saharan Africa. In $S^{3} R$ l applications working paper A03/14: Southampton Statistical Sciences Research Institute.

National Population Commission (NPC) [Nigeria]. (2014). Nigeria demographic and health survey 2013 (pp. 377-396). Abuja and Rockville: NPC and ICF International.

National Population Commission [Nigeria]. (2004). Nigeria demographic and health survey 2003. Calverton: National Population Commission and ORC Macro International.

Omariba, D. W. R., Beaujot, R., \& Rajulton, F. (2007). Determinants of infant and child mortality in Kenya: An analysis controlling for frailty effects. Population Research and Policy Review, 26(3), 299-321.

Omariba, W. R., Rajulton, F., \& Beaujot, R. (2008). Correlated mortality risks of siblings in Kenya: The role of state dependence. Demographic Research, 18(11), 311-336.

Rajaratnam, J. K., Marcus, J. R., Flaxman, A. D., Wang, H., Levin-Rector, A., Dwyer, L., et al. (2010). Neonatal, post-neonatal, childhood, and under-5 mortality for 187 countries, 1970-2010: A systematic analysis of progress towards Millennium Development Goal 4. Lancet, 375, 1988-2008.

Ronsmans, C. (1995). Patterns of clustering of child mortality in a rural area of Senegal. Population Studies, 49(3), $443-461$.

Rutstein, S. O. (2008a). The DHS wealth index: Approaches for rural and urban areas. In DHS working papers no. 60. Calverton: Macro International.

Rutstein, S. O. (2008b). Further evidence of the effects of preceding birth intervals on neonatal, infant, and under-five-years mortality and nutritional status in developing countries: Evidence from the demographic and health surveys. In DHS working papers no. 41. Calverton: Macro International.

Rutstein, S. O., \& Staveteig, S. (2014). Making the demographic and health surveys wealth index comparable. In DHS methodological reports no. 9 (pp. 1-59). Rockville: ICF International.

Rutstein, S. O., \& Winter, R. (2014). The effects of fertility behavior on child survival and child nutritional status: Evidence from the Demographic and Health Surveys, 2006-2012. In DHS analytical studies no. 37. Rockville: ICF International.

Saha, U. R., \& van Soest, A. (2011). Infant death clustering in families: Magnitude, causes, and the influence of better health services, Bangladesh 1982-2005. Population Studies, 65(3), 273-287.

Sastry, N. (1997a). Family-level clustering of childhood mortality risk in Northeast Brazil. Population Studies, 51(3), $245-261$.

Sastry, N. (1997b). A nested frailty model for survival data, with an application to the study of child survival in Northeast Brazil. Journal of the American Statistical Association, 92(438), 426-435.

Silva, R. (2012). Child mortality estimation: Consistency of under-five mortality rate estimates using full birth histories and summary birth histories. PLoS Medicine, 9(8), e1001296. https://doi.org/10.1371/journal.pmed.1001296.

Smith-Greenaway, E. (2013). Maternal reading skills and child mortality in Nigeria: A reassessment of why education matters. Demography, 50(5), 1551-1561. https://doi.org/10.1007/s13524-013-0209-1. 
Stewart, M. B. (2006). A Stata program for the Heckman estimator of the random effects dynamic probit model. http://www2. warwick.ac.uk/fac/soc/economics/staff/faculty/stewart/stata.

The DHS Program (2017). Protecting the privacy of DHS survey respondents. http://dhsprogram.com/What-We-Do/ Protecting-the-Privacy-of-DHS-Survey-Respondents.cfm. Accessed 14 Sept 2017.

UNICEF. (2015). Levels and trends in child mortality: Estimates developed by the UN Inter-agency Group for Child Mortality Estimation (IGME). New York: UNICEF.

Uthman, O. A., Uthman, M. B., \& Yahaya, I. (2008). A population-based study of effect of multiple birth on infant mortality in Nigeria. BMC Pregnancy and Childbirth, 8, 41. https://doi.org/10.1186/1471-2393-8-41.

Van Bodegom, D., Eriksson, U. K., Houwing-Duistermaat, J. J., \& Westendorp, R. G. J. (2012). Clustering of child mortality in a contemporary polygamous population in Africa. Biodemography and Social Biology, 58(2), 162-172. https://doi.org/10. 1080/19485565.2012.720445

WHO. (2015). Health in 2015: From MDG to SDG. Geneva: World Health Organization.

Winter, R., Akinlo, A., \& Florey, L. (2016). Trends in child health in Nigeria, 2003-2013. In DHS further analysis reports no. 103. Rockville: ICF International.

Zaba, B., \& David, P. H. (1996). Fertility and the distribution of child mortality risk among women: An illustrative analysis. Population Studies, 50(2), 263-278.

Zenger, E. (1993). Siblings' neonatal mortality risks and birth spacing in Bangladesh. Demography, 30(3), 477-488.

Submit your manuscript to a SpringerOpen ${ }^{\circ}$ journal and benefit from:

- Convenient online submission

- Rigorous peer review

- Open access: articles freely available online

High visibility within the field

- Retaining the copyright to your article

Submit your next manuscript at $>$ springeropen.com 